\title{
Knowledge Sharing and
}

\section{Development in a Digital Age}

Digital technologies are reaching ever further into remote parts of the world, changing how people access, use, and create information and knowledge. These changes may improve people's lives by making information more available, increasing avenues for political and economic engagement, and making governments more transparent and responsive. However, they also carry dangers of growing digital divides, threats to privacy, and the potential loss of diversity of knowledge. Governments, development agencies and civil society organisations need to work together to make knowledge more inclusive and open. This calls for investment in Information and Communications Technology (ICT) infrastructure, information professionals, and search and discovery tools.

The digital age and knowledge sharing

The next 15 years will see a rapid acceleration in new ways of creating, finding, and sharing, knowledge, and this will mean new opportunities and challenges for development agendas and efforts worldwide. Some estimate that by 2020, up to 100 billion devices will be connected to the internet, and that by 2025, nearly all of the world's population will be online. Through new technologies there are fewer barriers to joining in, knowledge creation is becoming more social and participative, and the line between consumer and producer is blurring. Crowdsourcing will continue to open up more spaces for participation in governance and in a range of development programmes.

In 2014, the Institute of Development Studies (IDS) conducted a horizon scanning research project to look at digital technologies and their potential impact on development over the coming 15 years. Using Foresight methods - a range of horizon-scanning tools and approaches based on scenario development - this research gathered knowledge and insights from a range of people working with digital technologies representing different perspectives: development agencies, government, librarians, ICT professionals and the private sector. Through interviews and two workshops, in London and Centurion, South Africa, participants identified key drivers of change and developed scenarios for different futures. From these, a 'preferred scenario' representing an ideal vision of the future emerged, and participants formulated strategies and policies to help realise that vision.

Opportunities for knowledge sharing and development Digital technologies will create opportunities for more effective development in the following ways:

- Access and availability: If the growing range of digital materials are made open and available it will improve information access, lower barriers to market entry, and enable a much wider cross section of the population to acquire knowledge skills and credentials through online learning. Digital repositories or other knowledge sharing systems will enable research and knowledge-based services relevant to development to be more available and accessible, and local research will be more visible. Methods such as crowdsourcing, which draws on knowledge and skills from large groups of ordinary people, will ensure
"The next 15 years will see a rapid acceleration in new ways of creating, finding, and sharing, knowledge, and this will mean new opportunities and challenges for development agendas and efforts worldwide." 
that research agendas are more aligned with needs on the ground.

\section{- Governance and service delivery: Digital} tools and crowdsourcing approaches can increase and improve citizen voice and government transparency allowing citizens to be more informed about budgets, issues, and upcoming decisions. Digital technologies will also improve service delivery. Data on health, education, infrastructure, social protection and other government sectors will be more abundant and more tools will be available to analyse them. Civil society can become more effective advocates and intermediaries through better knowledge sharing and availability of information.

\section{- Quality and relevance of knowledge:} Digital technologies have the potential for high impact by disrupting current regimes of knowledge production and publication, and enabling poor regions to become producers rather than net recipients of relevant development knowledge about themselves. This can happen if networks and incentive systems and structures are established that support local knowledge production, peer review and distribution.

- Wisdom of the crowd: Croudsourcing methods are becoming a powerful tool to help development initiatives become better targeted, informed and researched. Crowdsourcing can generate new innovative solutions by bringing together sectoral experts from throughout the globe with community members.

\section{Threats and barriers}

Digital technologies also pose threats to development principles of equality and democratic rights:

- Growing disparities: Perhaps the biggest threat posed by a digital age is that rather than leading to greater equalities of opportunities and outcomes, it creates new disparities or exacerbates existing ones. Current digital divides mirror economic ones and these could become reinforced with a growing knowledge divide based on levels of access. Without policies and strategies to develop capacities and skills among vulnerable groups, the poor will be left behind. At the other end of the spectrum, we are already seeing the way that the Internet's winner-take-all effect is creating a small group with extreme wealth and power. And there will likely be huge differences in infrastructure and skills between rural and urban areas in developing countries.

- Privacy, censorship and control: In the wrong hands digital technologies can add to the 'authoritarianism toolkit' by providing ever more effective methods of surveillance, censorship and control. Privacy issues arise not only through invasive spying regimes but can also be an issue if information is 'too' open. Public records and data on individuals' health or spending habits can provide valuable information for the public good, but could also be used maliciously.

- Information overload: Efficiencies in making knowledge available and accessible have reduced, in the minds of the public, the need for information intermediaries and professionals. When most information needs can be fulfilled online, the increasingly relevant skills that go into curating materials, making it visible, and helping to guide people to what they need, becomes largely invisible.

- Homogenisation of knowledge: There is a danger that digital trends will result in a global homogenisation of knowledge toward the mainstream. Rather than giving local knowledge a greater chance to flourish, a free flow of knowledge could increasingly edge out voices that do not fit within dominant discourses.

\section{Using digital technologies to achieve a more prosperous, just and equal society in Africa by 2030}

Created as part of a project using Foresight methods, this scenario outlines how digital technologies can be used to greatest effect to accelerate development progress in Africa by 2030 .

\section{What will the world look like in 2030 ?}

Who would have thought it possible, back in 2015 when they were drafting the Sustainable Development Goals (SDGs), how much could have changed for the better in 15 years? Internet is now seen as a basic right, and even the poor have a minimum allocation of internet access. This was accomplished largely through the pursuit of prudent policies based on a few principles that were agreed on globally and implemented by national governments, and crowdsourced feedback mechanisms that enabled citizens to hold the international community to account for delivering an open and fair digital society.
“Digital technologies have the potential for high impact by disrupting current regimes of knowledge production and publication, and enabling poor regions to become producers rather than net recipients of relevant development knowledge about themselves." 
For this to happen, agreements to build a global ICT-based knowledge infrastructure were drafted and set into motion through the mechanics of the SDGs framed back in 2015. Although global leaders held different views on the cost-benefit of extending ICT infrastructures to more remote regions, most nations have now extended internet access to over 90 per cent of their populations, with active involvement of government bodies down to the village level. For researchers, government policy and implementing bodies, and development practitioners, openness also includes access to research documentation, datasets and government records.

An Africa-wide repository of locally-produced research automatically harvests documents from universities and research institutes throughout Africa, making them easily available and searchable. A pan-African research body administers the system, and has set up a peer review system that ensures the quality of materials in the repository. In addition, under this research scheme, African national governments have implemented policies to incentivise publishing in the repository. The result has been a marked rise in local contributions to literature on local development, which has improved the quantity and relevance of development-todevelopment efforts, and helped to set new agendas for both research and development.

Information and data scientists, librarians and knowledge intermediaries play a vital role in this pan-African research council and its repository system. New documents and data sets are being produced in heaps, and information professionals are needed at all levels to make sure that they are all easily searchable and discoverable. They are also a much used resource to help guide people to the information they need.

Technology has also made education more widely available. Massive Open Online Courses (MOOCs) have not totally changed the education business model, but have become one of a number of important approaches in helping to increase access to good education. The availability of information and knowledge has also made it easier for students to find what they need even in remote areas. Most importantly, new models of knowledge sharing have enabled more African researchers to contribute to global online education systems, joining the ranks of globally famous online lecturers that previously came exclusively from Western universities. In addition, governments have prioritised capacity to use all the knowledge available at all levels of education.

Government services have also improved from online systems. Through crowdsourcing and large amounts of data, the government is able to get a much more granular view of citizens' needs and thus target policies and programmes more accurately. Budgets and procurement are all transparent for watchdog organisations to scrutinise, and through crowdsourcing we are able to participate in policy discussions.

The digital age has ushered in new opportunities, reaching all the way to remote villages, and this has resulted in a stronger global economy with a lot less inequality and poverty. Social entrepreneurship, Corporate Social Responsibility (CSR) and profit sharing with workers has become widespread and at the national and international levels incentives serve to increase competition and break monopolies.

With so much information available to all, privacy is an ongoing public debate. There are variations country by country on, for example, how much of your health information can be made available to government and to the public for medical research purposes. But in every case the general principle of the right to privacy stands, and debates about specific spheres of privacy are open and transparent.

Some worry that life and society nowadays are too much about data. That we are blind to problems that resist 'datafication', and much less able to find solutions. True, citizens insist that the algorithms that determine so much of our life must remain transparent, so that civil society groups can monitor the thoughts and values that go into crafting them. But as they get more and more sophisticated, sometimes it feels that we are being asked to trust that the computers have our best interest in mind. Mostly, though, it seems that the 'opt out' talk is about a discomfort with the amount of data we each produce and the potential for our data to someday fall into the wrong hands. Even though most people believe that government policies toward privacy, transparency, and data use are working well for now, it is good that these worries can be freely aired and discussed.
"Who would have thought it possible, back in 2015 when they were drafting the Sustainable Development Goals (SDGs), how much could have changed for the better in 15 years? Internet is now seen as a basic right, and even the poor have a minimum allocation of internet access." 


\section{Policy recommendations}

To go some way toward achieving this vision, we recommend policies and strategies in four areas:

- Cross-cutting principles: For technological change to benefit the poor and to close digital divides, strategies toward principles of universal access and inclusive knowledge are needed. The poor should participate in developing knowledge infrastructure and systems that benefit them. Research institutions, governments, and development organisations should pursue strategies toward open knowledge through better incentives, capacity development and advocacy. Openness needs to be balanced with ownership, privacy and security considerations, but currently tilts far to the closed side.

- Creating the right environment: Governments, regional bodies and international development agencies need strong cooperation on improving ICT-based knowledge sharing infrastructure, developing a common set of goals and meaningful metrics, and incentivising knowledge sharing across borders and institutions. This cooperation could be framed by the Sustainable Development Goals, which should more explicitly address and monitor digital opportunities and threats.

- Human capacity: Governments and development agencies should invest in the capacity of knowledge intermediaries, librarians, and information and data scientists working at the intersection of development, information science and governance. Universities and governments should incentivise African research and encourage publishing through cooperative, peer-reviewed open access platforms. School curricula from primary school upwards should emphasise digital literacy and skills

- Infrastructure and tools: Most of the above recommendations hinge on coordinated investment in ICT infrastructure at local, national, and regional levels by governments and development agencies. This investment should also be framed as part of the Sustainable Development Goals, and Financing for Development processes. This includes investment in developing more effective knowledge sharing systems and digital repositories. Ongoing improvements for search and discovery tools are needed to make them more powerful and intuitive. Crowdsourcing tools should be developed to help improve participation in public discourse and development research, and to improve government service delivery and accountability.

\section{Further reading}

Calhoun, K. (2014) Exploring

Digital Libraries: Foundations,

Practice, Prospects, London:

Facet

Castells, M. (2010) The Rise of the

Network Society, Chichester:

Wiley-Blackwell

Gregson, J.; Brownlee, J.;

Playforth, R. and Bimbe, N.

(2015, forthcoming) The Future of

Knowledge Sharing in a Digital

Age: Exploring Impacts and Policy

Implications for Development, IDS

Evidence Report, Brighton: IDS

Smith, M. and Reilly, K. (2013)

Open Development: Networked

Innovations in International

Development, Ottawa ON:

International Development

Research Centre/MIT Press

\section{Credits}

This IDS Policy Briefing was

written by Nason Bimbe, John

Brownlee, Jon Gregson and

Rachel Playforth. It was

produced as part of the IDS

Policy Anticipation, Response

and Evaluation programme

supported by UK aid from the

UK Department for International Development

The opinions expressed are those of the author and do not necessarily reflect the views of IDS or the UK government's official policies.

Readers are encouraged to quote and reproduce material from issues of IDS Policy Briefings in their own publication. IDS requests due acknowledgement and quotes to be referenced as above.

AG Level 2 Output ID: 258

(C) Institute of Development Studies, 2015 ISSN 1479-974X 